\title{
Relevance of Economic Field Microscope in Remote Rural Regions for Concurrent Observation of Malaria \& Inflammation*
}

\section{Deepak Bhattacharya}

Fight Malaria at Home, C/o Sri Radha Krishna, Bhubaneswar, India.

Email: oddisilab1@dataone.in

Received January $16^{\text {th }}, 2012$, revised February $25^{\text {th }}$, 2012; accepted March $10^{\text {th }}, 2012$

\begin{abstract}
Based on mono station use for $>12$ continuous years (since 1998) in drug resistant core endemic region, India, antiinflammatory effect on WBC is demonstrated using a simple; economic monocular microscope that can be used out in the open — using day light/lamp. Is infinitely helpful for rural clinicians and the administrations, in developing nations. Although indispensable, a field microscope has become expensive; is in short supply; there is a crying need in the rural and the remote.
\end{abstract}

Keywords: OMARIA; Field Microscopy; Inflammation Observation; WBC Architecture Alteration; Gametocydal; Plasmocidal

\section{Introduction}

Once upon a time the microscope was signature of learning; good health and omniscient. It now, is one of the devices that (may) rule the roost in research; tucked away from the public eye and delicately handled (expensive). In developing nations (viz., Latin America; Africa; India; S E Asia;) that have huge populations; year round high incidence of infestation; concurrent bacterial infections; and are also fund rich, this devise has good demand. However, cartridge based rapid detection kits have made so deep inroads into health care diagnostic systems that, a microscope has become a "optional"; a unaffordable referral tool specially in the rural and the remote. Is considered as a time consuming member, requiring learnt $\&$ acquired skill, that is (erroneously) perceived to yield little to the pocket and often not to the purse. In case of malaria in India, ultra high figures has been suggested [1]; even with ACT resistant mutant genotypes [2]. Whereas, using the on-foot; microscope method (not adopting the cartridges) we find that the ground reality (in the focus domain) to be only 3 cases out of every 10 sick (i.e., $1 / 3^{\text {rd }}$ ). Our decadal experience [3] has also been that at times, the rapid detection kits/tests (cartridge) yield "positive" in 10 out of 10 cases which all are negated by multi-disciplinary poly teams via the field/clinical microscope. And, "falls negative" reports have also started arriving on the horizon [4]. These be not "falls positive"

*There are no Conflict of interests. and/or "falls negative". These are "wrong result". Not permissible. We have also encountered lot many falls negative, but could not label them with an appropriate term. Therefore microscope is the sole reliable. The Indian National Rural Health Mission has no emphasis on the microscope, although the device generates sustained employment, in the rural and in the peri-urban regions. NRHM is fund rich. And, employment is anti-dote to economic recession and up-regulates malaria combat operations. Respective national policy makers have become oblivious. Target driven marketing and GDP oriented instant commerce has pushed this device of precision and surety out of the public eye, to a corner, and even out (considerately said). In present times, more funds are being ear-marked by each tropical nation; and more number of developed nations (from non malaria prone temperate climate region) are getting involved in malaria, including UNICEF [5]; The White House [6]; and Bill \& Bilinda Gates Foundation [7], than in any other malady. Such involvement is noted to follow a popular article (in Asia's leading News paper) by the present author [8]. New resistant strains are evolving [9]. Malaria, also engages the largest pool stock of medical and para-medical workers; has the largest geographical swath; highest number of afflicted persons on the globe at any given hour, in any given universal time zone; and keeps on hitting the news "headlines" for sad reasons. WHO prescribes the microscope as the sole diagnostic tool in malariasis. Yet, the cartridge rules. 


\section{Malaria \& Inflammation}

Clinicians do call (falling habit) for a WBC total count, and deviation from the normal range is anecdotally related to some "lurking/idiopathic pathology". No naked eye diagnosis is made on WBC's cross section basis. Whereas, the deviation (in architecture) is indeed seen by the pathologist's/microscopist's naked eye. Yet, neither is it declared, nor labeled. Presence/absence of gametocyte and their populations are not announced as yet. The treating clinician is unaware too. Can be done via the field microscope (sans any cost escalation) and preferably should be.

Inflammation, is that physiological state, whence the body turns "on" its defense mechanism. Host's defense being least oriented towards own RBC, in malariasis, inflammation is triggered high. Numerous cell lines \& organs get involved jointly and severally, resulting in spiraling inflammation syndromes mediated by multi-organs [10]; is marked by production of pro-inflammatory stable proteins via the MMP-9 pathway [11]; and, which is independent of pathology causing antibody [12] leading to "shut downs"; "refractile status"; unstoppably proceeding to fatality, as alike in sepsis and blood dyscarsia [13].

In status cerebral malaria, managing and overcoming innate-spiraling systemic inflammation is $>50 \%$ of the successful combat. Thence, hemodynamics is also in failinglfailed mode, and hence, WBC count also yield askew results. Consequently, gravity route of infusion and intramuscular injection are unavailable. Oral route in thence, the sole available, and it too cannot be adopted sans intubation device, due to deep seated morbidity; often with pulmonary distress. In clinical practice, appreciation of such gamut of issues is generally not encountered. Moreover, there are no internal medicine/s that can be used to down turn inflammation first and then kill \& clear hemoprotozoa sans any toxic effect. Limitations are noted, both of technology and in clinical practices. Managing inflammation has therefore been an acute challenge at clinical level. It is an up-coming international priority domain.

Post anti-malaria therapy, infestation may go away and not the inflammation. Conventional anti-malarial therapy (viz., CQ, MDTs and ACTs and Lumefantrine) do not assist down-turn of inflammation. They are toxic; expensive and cause side-effects [14]. In-fact, they heighten systemic inflammation. Side effects are also associated with (such) drug induced inflammation. The pregnant; infant and the mother are as much severely affected by malaria and also by inflammation due the toxic moieties of these conventional therapies. All this can be visioned via the field microscope, in real time by the treating clinician. And mother-\&-child care is a priority national funded health care sector, across the world.

\section{General Pathology \& Inflammation}

In the trop-equatorial regions of the developing nations, due habitat and living conditions there be poly infestations viz., helminthes; gut protozoa; and or poly bacterial infections (typhosa being common in India) cause \& retain inflammation, even post therapy. Further, cancer; pulmonary/urinary/ENT/dental, etc., infections are rising in numbers (census based), and off late (due living conditions; meteorology; \& ecology) in the Indian sub-continent, chickengunya (alpha-virus CHIK-V) and Dengu (flavivirus) are also re-ported concurrently along-with malariasis (except cancer). Most viral infestation and (with year round presence) CMVs in particular, are associated with intense inflammation. Whereas, the same microscope and blood slide can be used to announce the persistence of inflammation; associated atypicalities; the primary and the secondary causes; and prognosis thereof. It will lead to simplification and economies of prescription; timely referrals. The simple field microscope is yet to see its "best day".

World-wide, there is a crying need to have at hand a product and a sure-simple (naked eye) evidencing methodology to clinically determine inflammation down-turn status during any therapy and pathology. Altruistic administrations (such as India) is capable of investing. So, there is an emergent need; a large demand-application space. Further, inflammation research is an upcoming domain of intent investment of mind \& money.

The geriatric physiology is a ever present case of inflammation. Numerically the geriatric group is expanding world wide; fiscally they are enabled better. And, vis-àvis inflammation (specially pediatric and/or geriatric inflammations), the microscope is yet to play its due eminent role. Even then, non put now the microscope as the logo on their official letter head.

\section{Materials \& Methods}

1) OMARIA a new Indian bio-medicine is taken as oral drug [15]. It is selected for it is potent anti-inflammation cum anti-malarial efficacy [16,17]; is reported to be highly effective against drug resistant African field isolates [18]; 2) We take a simple, economic clinical monocular field microscope of 30 years vintage to demonstrate down-turn of inflammation (apart anti-gametocyte; anti-merozoit and anti-trophozoit effect). It can be operated in day-light under shade and in camps using battery operated torch light; 3 ) a representative pediatric case to demonstrate the in-vivo concurrent anti-inflammation efficacy (along with anti-malarial) and above all the basis of naked eye evidence in real time cases and 4) near-infant candidate/pediatric malaria $(<5 \mathrm{yr})$ is associated with severe anemia/more in boys [19]; coma arises quickly [20]; and cerebral status manifests early and dif- 
ferently from that of the adults [21]; and we also take 5) the WWW net as the economic counter validating resource portal. Deft use of field microscopy assists "Bottom Up model”, which is vital in relevant drug discovery.

\section{Microscope Observations}

Our Figures 1-3 are that of peripheral blood slide of one BM (Ballav Muduli), Hindu, male child of age 2 - 3 yr, of village Gunthaguda, Dist. Koraput, Odisa, India, Dt. 2807-2008. Since his birth, he had never contacted malaria; although he lives bare foot, skimpily dressed; in ramshackle mud walled, hay thatched house; in core drug resistant malaria endemic zone of India. On first contacting malaria he started experiencing acute recurrent bouts of deffervescence, sinking with every recurrent episode. Blood was drawn on 28-07-2008, from which thick blood smear slides were made (Figure 1). It shows full grown male and female gametocytes and a field full with parasite rings having double chromatin, which is the signature of Plasmodium falciparum. Pathologist/microscopist mark such infestation as a status of $(++++)$. In other words, child BM was very acutely infested. BM's parents were given few OMARIA caps. (28/07/08, PM), which they were required to open, take out the rind powder, soak it in water with sugar and common salt and cajole feed the supernatant orally to the acutely febrile child. This is because OMARIA "00" size cap., is very large; infants cannot swallow; harsh in taste. Such at home; self made soak-extract (OMARIA supernatant is harsh in taste) could only sporadically be forced fed to the child through the night.

The Next day the child became playful, asymptomatic, with no recurrence of deffervescence bouts. Microscope indicates that gametocytes can/do remain in circulation of the drug treated cases, who also be asymptomatic, particularly children [22]. Thereafter, for next consecutive 3 days, at a near intermission of 24 hours his blood was re-drawn and slides remade. Slides Dt. 30-07 -2008 i.e. $48^{\text {th }}$ hour post $1^{\text {st }}$ draw (Figure 2) shows degenerating gametocyte and lessening of $p f$ rings (the pathological status being +++ ). The drug is seen to be killing the gametocytes and also the RBC specific protozoa, and no hemolysis. Our Figure 3, is of the slide made at about $96^{\text {th }}$ hour post $1^{\text {st }}$ dose of OMARIA. It shows "all clear". In other words, kill \& clearance of developing phase parasites follow similar OMARIA effect on gametocytes. Whereas, the current range of drugs that are gametocydal are toxic and pro-inflammatory and non-specific [23]. OMARIA is not.

\section{Findings}

In Figures 1 and $\mathbf{2}$ the edges of the lymphocytes (WBCs) appear diffused, having enlarged cross section, with ra- dians like impression. It is a state of challenge by infestation. It is status inflammation effect on WBC sub populations, visualized by the naked eye in real time at clinic level, by the treating clinician. This will help in decision making pertaining to retaining a patient or discharging. In Figure 3 (which is post clearance by OMARIA), we see the edges as crenated/crimped, with shrinkage in gross cross section. It is that of unchallenged/normal state. Inflammation has waned. Although OMARIA kills and clears gametocytes of either sex ahead of all other circulating hemoprotozoas, WBC architectural inflammationalteration is visually more related to the other groups of

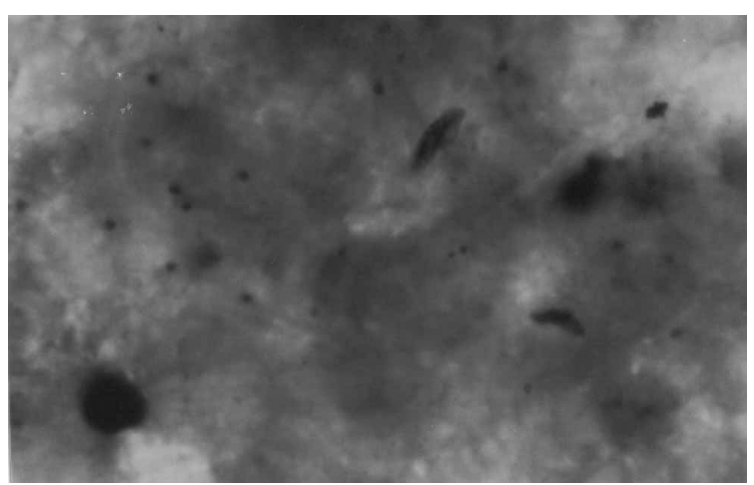

Figure 1. Microscope photo at $24^{\text {th }}$ hour.

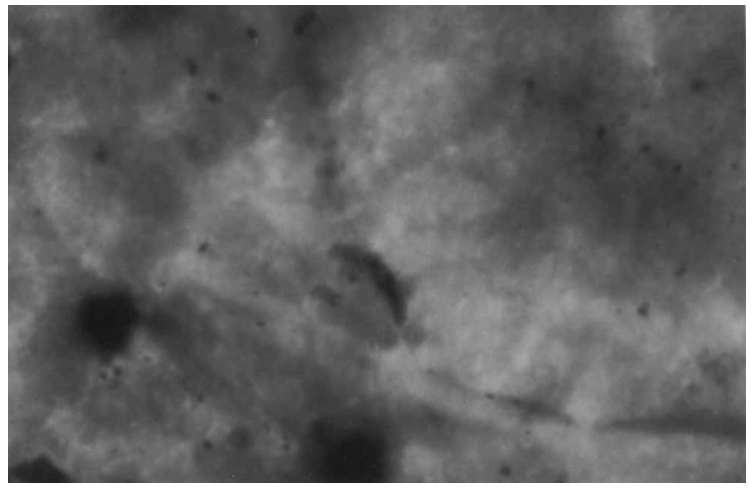

Figure 2. Microscope photo at $36^{\text {th }}$ hour.

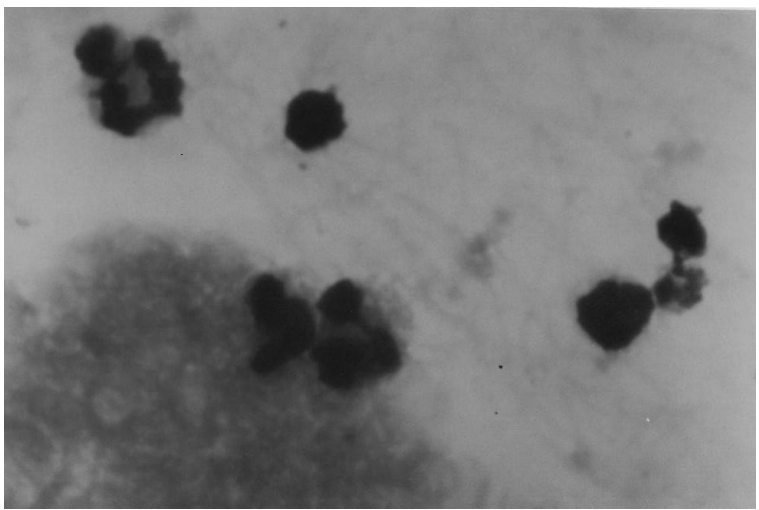

Figure 3. Microscope photo at $48^{\text {th }}$ hour. 
the circulating parasites.

\section{Discussions}

For the benefit of the rural clinicians/malariologists/pathologists/microscopists, we reproduce an artist's impression of a Lymphocyte (Figure 4) in particular, and an scanning electron microscope pictograph (Figure 5) of a healthy or unchallenged WBCs. Both been downloaded from the WWW with thanks [24], which confirms the architecture at normal/unchallenged/non-inflammation state. So, there is a remarkable alteration in the lymphocyte's architecture between Figures $\mathbf{2}$ and $\mathbf{3}$.

Specially, the geriatric is almost in a constant state of inflammation, while the pediatric is not. Allotropy is predominant in pediatric stages [25]. Age; habit (profession); habitat based variations can all be observed and studied - in relation to therapy. Therefore, the clinician can make better evidence based decisions. Malaria vaccine yet being some way afar $[26,27]$ mini rural efforts

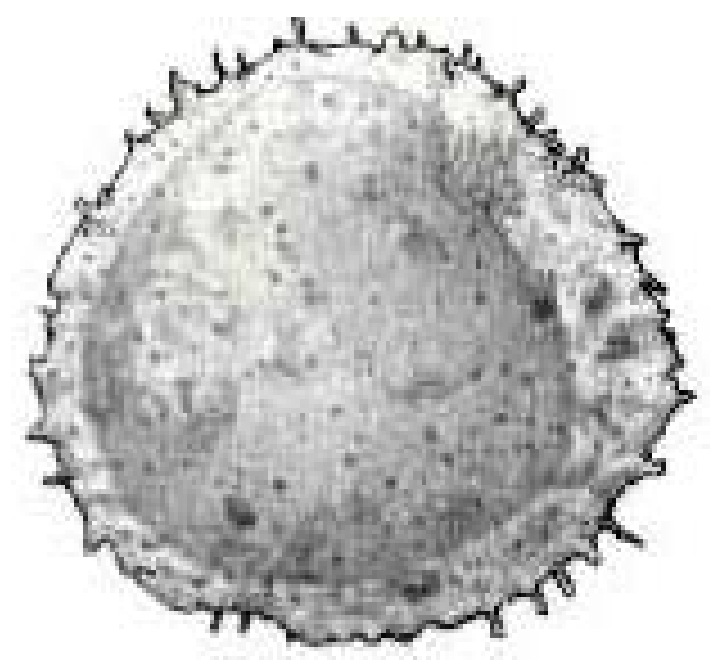

Figure 4. Artist impression of an lymphocyte.

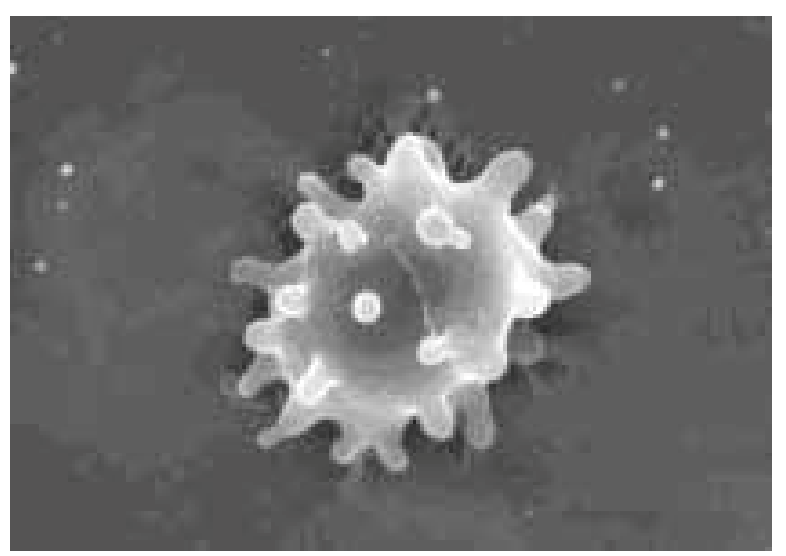

Figure 5. Scanning electron image as in available in literature as are available in remote-rural regions. like "Fight Malaria at Home" (1998; see Ref. [15]); followed by giant multi-lateral initiatives MIM;1995-1996 [28]; "Roll Back Malaria” WHO, 2008 [29]; etc., offers opportunity. Again, in the upcoming era(s) of holistic medicine \& medical herbalism [30] the role of the microscope has not been talked about. Ours is also a case of herbal medicine and field microscope-complementing relevance. There may be numerous mini/macro efforts. All such need to be brought to light; amalgamated; and assisted under a wishful "global initiative in field microscope-GIM".

Further, a rural clinician can rarely afford a microscope; and the para-medics, surely not. Yet, if they (under state funded national projects) be armed with robust, simple microscopes, then combating; arresting and rolling back infestations \& inflammation would be a shade easier an task, world wide. We use WWW sources (also are candidate posters) as because, microscopists/pathologists/one man operated rural \& remote clinics; mobile units (most do not have power) do not have access to expensive publications and whereas can access such referral portal and images by visiting cyber café in nearby towns (self education); and/or the phamplets supplied by the microscope maker; etc. (sponsored education).

Long period in-field use of simple microscopes also indicate that, CQ; ACTs; \& MDTs do not down turn inflammation even in drug sensitive cases; even in repeat visiting cases. Further, in malaria + bacterial infections and/or malaria + gut infestations and in any combination, the inflammation effect on the WBCs can be directly evidenced. Adopting such principles and practices, we have observed that concurrent use of 4-Acetamedophenol (paracetamol) with any school/group of anti-malarial @ $250-500 \mathrm{mg} / 60 \mathrm{Kg}$ of body weight (1-to-3 doses in 48 hr) also leads to anti-inflammation effect on the WBC sub-populations; better drug-dose efficacy and is safe (supporting information). Observations also indicates that, between the male and the female gametocytes, predominance of male gametocytes indicate few mild nonrelated symptoms; while predominance of female gametocytes is almost asymptomatic. Prima-facie OMARIA seem to more early act on the male (than the female) from ventral side, with alterations. Field microscopy supports our evidence based drug development effort, that, systemic acute inflammation is caused by parasitisation of the RBC and retained upto trophozoit lysis stage; and not by mere presence in the blood fluid.

\section{Conclusions}

Long period, mono-station, in-field microscopy got to us numerous new finds and has also enabled us variously. Figures 1 and $\mathbf{2}$ evidences that, 1) inflammation due to 
pathology does register on the WBCs, architecture which can be seen by the naked eye using an ordinary microscope (even monocular of vintage make). Figure 3 evidences that in-vivo, in humans 2) anti-inflammation activity of the therapy also does register on the WBC's architecture which too can be seen by the naked eye 3) Microscope cum mono blood slide can be used at clinical level to simultaneously determine infestation and specially about inflammation statuses via the naked eye as part of simonic evidence by the treating clinician; specially in all individual specific response pathologies like malaria, 4) in-flammation effect on the architecture of the WBC sub-populations can also be evidenced in many a other pathology 5) similarly, pro-inflammation effect if any, of any drug, can also be observed, pre-during-and post therapy. 6) Apart in human \& veterinary, such concept and methods are also applicable in re-search models 7) clinicians can directly assist drug controllers and drug discoverers 8) making; marketing; and operating microscopes will generate employment and prosperity in the rural; remote and in the peri-urban regions, world wide, apart from sure diagnosis and good pre-scriptions. For genuine community welfare, we advocate a robust (not delicate) operation enabling ultra economic device. That will then be a great tool for the mass infestations/infections afflicted nations. An international funded scheme of one village-one microscope $(1 \mathrm{v}-1 \mathrm{~m})$ will go a long way in effectively down turning man-hour loss; treatment cost over-runs and physical comfort to the afflicted (all these are now happening on a massive scale).

\section{Acknowledgements}

Thanks to Dr. P.K.Sahu (CIFA); Dr. Sudhansu Misra, CMRC, both Bhubaneswar. This communication is Dedicated to Late Mr. Samiran Biswas; microbiologist cum microscopist Govt., Capital Hospital, Bhubaneswar, India. He lent his spare vintage microscope, which remains with operation Fight Malaria at Home. Also B. M. Bhuyan, Secretary, Indian Red Cross Society, Koraput, has been very instrumental in operation OMARIA since inception, till date; along with Narayanpatna, Block welfare officer (see: http://news.bbc.co.uk/2/hi/south_asia/988316.stm.) (2000) \& Bhattacharya 2006 \& 2011.

\section{REFERENCES}

[1] N. Dhingra, P. Jha, V. P. Sharma, A. A. Cohen, R. M. Jotkar, P. S. Rodriguez, et al., "Adult and Child Malaria Mortality in India: A Nationally Representative Mortality Survey,” Lancet, Vol. 376, No. 9754, 2010, pp. 1768-1774. doi:10.1016/50140-6736(10)60831-8

[2] K. M. Prashant, J. Hema, V. Neena, K. S. Surya, E. Alex, M. B. Rajendra, C. S. Harish, L. S. Patrick, P. D. Aditya and K. B. Virendra, “Mutant pfcrt 'SVMNT' Haplotype and Wild Type Pfmdr1 'N86' Are Endemic in Plasmodium vivax Dominated Areas of India under High Chloroquine Exposure,” Malaria Journal, Vol. 11, 2012, p. 16. doi:10.1186/1475-2875-11-16

[3] P. Nageshwar, “India Claims Malaria Cure,” BBC, 2000. http://news.bbc.co.uk/2/hi/south_asia/988316.stm

[4] Z. Tekeste, M. Workineh and B. Petros, "Comparison of Paracheck Pf ${ }^{\circledR}$ Test with Conventional Light Microscopy for the Diagnosis of Malaria in Ethiopia,” Asian Pacific Journal of Tropical Disease, Vol. 1, No. 3, 2012, pp. $1-3$.

[5] UNICEF-White House Summit on Malaria, New York, 2006. http://www.unicef.org/health/index_37773.html

[6] President's Malaria Initiative. http://georgewbush-whitehouse.archives.gov/infocus/mal aria/

[7] Bill \& Milinda Gates Foundation, Grand Challenges in Global Health.

http://www.grandchallenges.org/explorations/Pages/intro duction.aspx

[8] D. Bhattacharya, "Fight Malaria at Home,” Express Pharma, Bombay, 1-15 May 2006. pp. 1-15. http://www.expresspharmaonline.com/20060515/research 02.shtml

[9] J. B. Lekana-Douki, S. D. Dinzouna Boutamba, R. Zatra, S. E. Zang Edou, H. Ekomy, U. Bisvigou and F. S. ToureNdouo "Increased Prevalence of the Plasmodium falciparum Pfmdr1 86N Genotype among Field Isolates from Franceville, Gabon after Replacement of Chloroquine by Artemether Lumefantrine and Artesunate-Mefloquine," Infection, Genetics and Evolution, Vol. 11, No. 2, 2011, pp. 512-517. doi:10.1016/j.meegid.2011.01.003

[10] D. Bhattacharya, "OMARIA-A New Herbal Anti Malarial,” The Pharma Review, Vol. 1, No. 1, 2002, pp. 80-84.

[11] H. Nagaset and J. F. Woessner, "Matrix Metalloprotinases,” Journal of Biological Chemistry, Vol. 274, No. 31, 1999, pp. 21491-21494.

[12] M. Prato and G. Giribaldi, "Matrix Metalloproteinase-9 and Hemozoin: Wedding Rings for Human Host and Pf Parasite in Complicated Malaria,” Journal of Tropical Medicine, Vol. 2011, 2011, p. 6. doi:10.1155/2011/628438

[13] D. Bhattacharya, “A New Anti-Malarial Cum Wide Spectrum Anti-Viral: Integrated Approach for Whole Village Comprehensive Cure Cum Prevention,” In: S. N. Patro, Ed., 9th Orissa Science Congress, Bhubaneswar, December 2005, pp. 76-84.

[14] S. Toovey and A. Jamieson, “Audiometric Changes (Neurotoxicity) Associated with the Treatment of Uncomplicated Falciparum Malaria with Co-Artemether,” Transactions of the Royal Society of Tropical Medicine and Hygiene, Vol. 98, No. 5, 2004, pp. 261-267.

[15] D. Bhattacharya, "Fight Malaria at Home," Asian Pacific Journal of Tropical Diseases, Vol. 1, No. 2, 2011, pp. 142-149.

[16] M. Dell’Agli, G. V. Galli, Y. Corbett, D. Taramelli, L. 
Lucantoni, A. Habluetzel, O. Maschi, D. Caruso, F. Giavarini, S. Romeo, D. Bhattacharya and E. Bossisio, "Antiplasmodial Activity of Punica granatum L. Fruit Rind,” Journal of Ethnopharmacology, Vol. 125, No. 2, 2009, pp. 279-285. doi:10.1016/j.jep.2009.06.025

[17] M. Dell’Agli, G. V. Galli, M. Bulgari, N. Basilico, S. Romeo, D. Bhattacharya, D. Taramelli and E. Bosisio, "Ellagitannins of the Fruit Rind of Pomegranate (Punica granatum) Antagonize in Vitro the Host Inflammatory Response Mechanisms Involved in the Onset of Malaria,” Malaria Journal, Vol. 9, 2010, p. 208. doi:10.1186/1475-2875-9-208

[18] J. B. Lekana-Douki, D. Bhattacharya, R. Zatra and S. T.-N. Fousseyni, "Indian Anti-Malaria OMARIA Is Effective against African Drug Resistant P. falciparum Field Isolates and Laboratory Strains; without Toxicity,” International Journal of Clinical Medicine, Vol. 3, No. 1, 2012, pp. 1-8. doi:10.4236/ijcm.2012.31001

[19] W. S. Akhwale, J. K. Lum, A. Kaneko, H. Eto, C. Obonyo, A. Björkman and T. Kobayakawa, "Anemia and Malaria at Different Altitudes in the Western Highlands Of Kenya,” Acta Tropica, Vol. 91, No. 2, 2004, pp. 167175. doi:10.1016/j.actatropica.2004.02.010

[20] C. R. J. C. Newton, T. T. Hien and N. White, “Cerebral Malaria,” Journal of Neurology, Neurosurgery \& Psychiatry, Vol. 69, 2000, pp. 433-441. doi:10.1136/jnnp.69.4.433

[21] R. Idro, N. E. Jenkins, C. R. J. C. Newton, "Pathogenesis, Clinical Features, and Neurological Outcome of Cerebral Malaria,” Lancet Neurology, Vol. 4, No. 12. 2005, pp. 827840. doi:10.1016/S1474-4422(05)70247-7

[22] J. T. Bousema, L. C. Gouagna, C. J. Drakeley, A. M. Meutstege, B. A. Okech, I. N. J. Akim, J. C. Beier, J. I.
Githure and R. W. Sauerwein, "Plasmodium falciparum Gametocyte Carriage In Asymptomatic Children in Western Kenya,” Malaria Journal, Vol. 3, 2004, p. 18. doi:10.1186/1475-2875-3-18

[23] C. L. Peatey, D. Leroy, D. L. Gardiner and K. R Trenholme, "Anti-Malarial Drugs: How Effective Are They against Plasmodium falciparum Gametocytes?” Malaria Journal, Vol. 11, 2012, p. 34. doi:10.1186/1475-2875-11-34

[24] D. Tagliasacchi and G. Carboni, "Drawings of Michele Pirazzini,” Translation by David W. Walker, 1997. http://www.funsci.com/fun3_en/blood/blood.htm\#23

[25] E. M. W. Billig, W. P. O’Meara, E. M. Riley and F. E. McKenzie, "Developmental Allometry And Paediatric Malaria,” Malaria Journal, Vol. 11, 2012, p. 64

[26] L. Veronic and P. Karanis, "Malaria Vaccine: Looking Back and Lessons Learnt,” Asian Pacific Journal of Tropical Biomedicine, Vol. 1, No. 1, 2011, pp. 74-78. doi:10.1016/S2221-1691(11)60072-5

[27] L. Schwartz, G. V. Brown, B. Genton and V. S. Moorthy, "A Review of Malaria Vaccine Clinical Projects Based on the WHO Rainbow Table,” Malaria Journal, Vol. 11, 2012, p. 11. doi:10.1186/1475-2875-11-11

[28] Multilateral Initiative on Malaria. http://www.mimalaria.org/eng/historyandevolution.asp

[29] World Health Organization, "Sixty-first World Health Assembly,” WHO, Geneva, 2008. http://www.rbm.who.int/.

[30] S. J. Ameh, O. O. Obiageri, B. C. Peace and G. S. Karnuis, "Medical Herbalism and Herbal Clinical Research: A Global Perspective,” British Journal of Pharmaceutical Research, Vol. 1, No. 4, 2011, pp. 99-123. 